\title{
Isolation of (+)-Catechin from Acacia Catechu (Cutch Tree) by a Convenient Method
}

\author{
M. A. Hye ${ }^{1}$, M. A. Taher ${ }^{1}$, M.Y. Ali ${ }^{2}$, M.U. Ali ${ }^{2}$, and Shahed Zaman ${ }^{2 \dagger}$ \\ ${ }^{1}$ BCSIR Laboratories, Rajshahi-6206, Bangladesh \\ ${ }^{2}$ Department of Chemistry, Rajshahi University, Bangladesh
}

Received 24 November 2008, accepted in final revised form 27 March 2009

\begin{abstract}
Biologically important polyphenol (+)-catechin was isolated from catechu, the extract of the red heartwood of Acacia Catechu tree (Khoiyer tree). The isolation procedure was developed to get better yield (25\%) and to reduce the isolation cost and time. The structure of the isolated $(+)$-catechin was confirmed with several spectral analyses and chemical studies.
\end{abstract}

Keywords: Acacia Catechu; (+)-catechin; Polyphenol.

(C) 2009 JSR Publications. ISSN: 2070-0237 (Print); 2070-0245 (Online). All rights reserved.

DOI: $10.3329 /$ jsr.v1i2.1635

\section{Introduction}

Catechu (or cutch), a hot water extract of red heartwood of Acacia Catechu Willd [1] is brown coloured material with bitter taste. It is produced in the cottage industries in good amount in the northern part of Bangladesh, especially in Rajshahi where Acacia Catechu grows in abundance. Unfortunately, only a portion of it is utilized as species with betel leaves for chewing. It has some medicinal values [2]. Faruq and co-workers [3] derived a simple method for piece-dying cotton fabric using catechu.

The chief constituents [4] of the red heartwood are catechin and catechu tannic acid along with small proportion of brown coloring matter. It also contains tannin, flavotannin, gallotannin, phloratannin etc [2]. (+)-Catechin is a substance, which diminish or arrest the action of some hormones [4]; thus "tyronorman" injected with thyroxin suppresses the rise in basal metabolism.

The tanning property of catechin in human skin may be supposed to be the active ingredient for the treatment of leucoderma (shiti) [5]. Catechin has antihormone activity [6]. Further its activity has also been correlated with those of vitamin P [6].

\footnotetext{
${ }^{\dagger}$ Corresponding author: zmshahed@yahoo.com
} 
It is evident from the literature survey that the catechin is a biologically important polyphenolic compound. Thus to isolate it from natural sources for the welfare of human being will be a welcome effort. The conventional method [7] for the isolation of (+)catechin from catechu is labourious, costly and low yielding (14.2 - 17.2\%). Therefore, attempt has been made in this work to develop the cost-effective isolation procedure for (+)-catechin from Acacia Catechu.

\section{Materials and Methods}

Solvent purification: Solvents used during the work were purified by distillation at the boiling point of the respective solvents. Evaporation of solvents was carried out on a Rotary vacuum evaporator under reduced pressure at bath temperature not exceeding $60^{\circ} \mathrm{C}$. The purity of the compounds was tested by analytical thin layer chromatography (TLC) on silica gel $60 \mathrm{GF}_{254}$ cards and the spots were made visible by exposure to UV light.

Melting point: A Reichart micro melting point apparatus was used for recording the melting points. Care was taken to ensure that the heating was done steadily.

${ }^{l}$ H-NMR spectra: The ${ }^{1} \mathrm{H}-\mathrm{NMR}$ spectra were recorded on a Bruker AM 300 FT NMR, AM 400 FT NMR and AM 500 FT NMR spectrometers using TMS (Trimethylsilane) as an internal standard.

Mass spectra: The mass spectra were registered on a Varian-MAT 112S and Finnigan MAT-112 and 312A double focusing mass spectrometers connected to DEC PDP 11/34 and IBM-AT compatible PC based system, respectively. Electron Impact (EI), Peak matching and Fast Atom Bombardment (FAB) experiments were performed on MAT312A mass spectrometers.

Infrared spectra: Infrared spectra were recorded on a PYE-UNICAM SP3 IR spectrophotometer. Spectra were taken in $\mathrm{KBr}$ pellets.

UV spectra: UV spectra were recorded on a LKB 4053 Ultraspec K Ultraviolet/Visible spectrophotometer.

${ }^{13} C$-NMR spectra: The ${ }^{13} \mathrm{C}-\mathrm{NMR}$ spectra were recorded at 75,100 and $125 \mathrm{MHz}$ on a Bruker AM 300 FT NMR, AM 400 FT NMR and AM 500 FT NMR spectrometers, respectively.

\subsection{Preparation of the material}

Collection of raw materials: Acacia catechu tree was collected from the botanical garden of BCSIR Laboratories, Rajshahi.

\subsubsection{Separation of catechu [8]}

One kg of the dried chips of Acacia catechu was taken in an aluminium pot to which ten litres of water were added so that the chips completely immersed under water. It was 
boiled over an open fire for four hours and allowed to stand for 24 hours so that more catechu might diffuse into the water. The extract was decanted off in a pot and was filtered through a fine muslin cloth to remove wood chips and other suspended materials. The filtrate was evaporated and the residue obtained was air dried and weighed $(180 \mathrm{~g})$. Yield of catechu was $18 \%$.

\subsubsection{Isolation of (+)-catechin}

Isolated catechu $(150 \mathrm{~g})$ was taken in a five-litre stainless steel beaker containing one litre distilled water. It was boiled with constant stirring for complete dissolution and filtered through a filter paper. Then it was evaporated to $500 \mathrm{ml}$ and allowed to stand for 24 hours. The obtained precipitate was filtered using a filter paper. The aqueous filtrate was rejected. The residue was dissolve in ethanol and filtered. The ethanolic solution was evaporated to dryness and the residue was dissolved into hot water $(500 \mathrm{ml})$. It was allowed to stand for 24 hours. The precipitate was filtered and dried in air (m.p. $95-6^{\circ} \mathrm{C}$, yield $37.5 \mathrm{~g}, 25 \%$ ). The process of re-crystallization from water was repeated thrice. On drying over phosphorus pentoxide the melting point of isolated (+)-catechin raised to 174$5^{\circ} \mathrm{C}$. Mixed melting point with an authentic sample did not show lowering.

\subsubsection{Thin layer chromatography of (+)-catechin [9]}

The isolated (+)-catechin and authentic samples were applied on a silica gel 60G plate using alcohol and develoved with toluene, ethyl acetate, formic acid (10:8:1). Spots were developed in an iodine chamber. Both the compounds showed single spot $\left(R_{f}=0.27\right)$.

\subsection{Spectral analysis of (+)-catechin}

IR spectra: IR spectra [ $\left.\mathrm{v}_{\max }(\mathrm{KBr})\right]$ showed band at 2600-3400 (broad), 1620, 1520, 1470, 1380, 1280, 1240, 1150, 1120, 1080, 1020, $820 \mathrm{~cm}^{-1}$.

Mass spectra: The mass spectra showed maximum at 290 and minimum at 55 . The other fragments were seen at 139,138,110,152, 151 and 123. The molecular mass corresponding to 290 was observed.

UV spectra: UV spectra ( $\lambda_{\max }$ [methanol]) showed maxima at $277 \mathrm{~nm}$ and $220 \mathrm{~nm}$.

${ }^{1} \mathrm{H}-\mathrm{NMR}\left(400 \mathrm{MHz}\right.$, acetone- $\left.d_{6}\right):{ }^{1} \mathrm{H}-\mathrm{NMR}$ spectra showed peaks at $\delta_{T M S} 4.56[\mathrm{H}-2, \mathrm{~d}$, $\left.\mathrm{J}_{(\mathrm{H}-2, \mathrm{H}-3 \mathrm{a})} 7.8 \mathrm{~Hz}\right], 4.00$ [H-3, ddd, $\mathrm{J}_{(\mathrm{H}-3 \mathrm{a}, \mathrm{H}-4 \mathrm{e})} 5.58 \mathrm{~Hz}, \mathrm{~J}_{(\mathrm{H}-3 \mathrm{a}, \mathrm{H}-4 \mathrm{a})} 8.50 \mathrm{~Hz}, \mathrm{~J}_{(\mathrm{H}-3 \mathrm{a}, \mathrm{H}-2 \mathrm{a})} 7.80$ $\mathrm{Hz}], 2.54$ [H-4a, dd, $\left.\mathrm{J}_{(\mathrm{H}-4 \mathrm{a}, \mathrm{H}-3 \mathrm{a})} 8.50 \mathrm{~Hz}, \mathrm{~J}_{(\mathrm{H}-4 \mathrm{a}, \mathrm{H}-4 \mathrm{e})} 16.10 \mathrm{~Hz}\right], 2.90$ [H-4e, dd, $\mathrm{J}_{(\mathrm{H}-4 \mathrm{e}, \mathrm{H}-3 \mathrm{a})}$ $\left.5.50 \mathrm{~Hz}, \mathrm{~J}_{(\mathrm{H}-4 \mathrm{e}, \mathrm{H}-4 \mathrm{a})} 16.10 \mathrm{~Hz}\right], 5.87$ [H-6, d, $\left.\mathrm{J}_{(\mathrm{H}-6, \mathrm{H}-8)} 2.3 \mathrm{~Hz}\right], 6.01\left[\mathrm{H}-8, \mathrm{~d}, \mathrm{~J}_{(\mathrm{H}-8, \mathrm{H}-6)} 2.3\right.$ $\mathrm{Hz}], 6.89$ [H-2', d, $\left.\mathrm{J}_{\left(\mathrm{H}-2^{\prime}, \mathrm{H}-6^{\prime}\right)} 1.95 \mathrm{~Hz}\right], 6.79$ [H-5', d, $\left.\mathrm{J}_{\left(\mathrm{H}-5^{\prime}, \mathrm{H}-6^{\prime}\right)} 8.07 \mathrm{~Hz}\right], 6.73$ [H-6', dd, $\mathrm{J}_{(\mathrm{H}-}$ $\left.\left.6^{\prime}, \mathrm{H}-2^{\prime}\right) 1.94 \mathrm{~Hz}, \mathrm{~J}_{\left(\mathrm{H}-6^{\prime}, \mathrm{H}-5^{\prime}\right)} 8.19 \mathrm{~Hz}\right]$ and 8.00 (phenolic protons, $\mathrm{m}$ ).

${ }^{13} \mathrm{C}-\mathrm{NMR}\left(500 \mathrm{MHz}\right.$ DMSO): Carbon atoms showed peaks at $\delta_{T M S} 27.7(\mathrm{C}-4), 66.3(\mathrm{C}-$ 3), 80.9 (C-2), 93.9 (C-6), 95.1 (C-8), 114.5 (C-2 ), 115.1 (C-5 ), 18.4 (C-6 ) and other aromatic carbons showed peaks at $\delta$ of $99.1,130.6,144.6,144.8,155.3,156.1$ and 156.4. 


\subsection{Alkali fusion of (+)-catechin [10]}

The isolated $(+)$-catechin $(0.1 \mathrm{~g})$ dissolved in ethanol $(10 \mathrm{ml})$ was refluxed with $50 \%$ alcoholic $\mathrm{KOH}(20 \mathrm{ml})$ for six hours. The reaction mixture was neutralized with $6 \mathrm{~N} \mathrm{HCl}$ and extracted with ether. A portion of ether extract was treated with 5\% sodium bicarbonate solution. Acidification and extraction of the sodium bicarbonate solution with ether gave no detectable substance.

The remaining ether extract was treated with $1 \%$ sodium hydroxide solution. Neutralization of the alkali layer with $5 \% \mathrm{HCl}$ followed by extraction with ether gave $0.043 \mathrm{~g}$ of white precipitate which after crystallization from $\mathrm{H}_{2} \mathrm{O}$ gave $0.039 \mathrm{~g}$ of phloroglucinol (m. p. $\left.220^{\circ} \mathrm{C}\right)$.

The aqueous layer was then concentrated and allowed to stand for 24 hours to give a brown precipitate $(0.0519 \mathrm{~g})$. On re-crystallization from hot water this gives protocatechuic acid, m.p. $199^{\circ} \mathrm{C}$.

\subsection{Methylation of $(+)$-catechin [11]}

$(+)$-Catechin was methylated with dimethyl sulphate. The yield of the methylated $(+)-$ catechin was $81 \%$. The melting point of the methylated product (m.p. $144-6^{\circ} \mathrm{C}$ ) corresponds to 5,7,3,4-tetra methyl ether of (+)-catechin [19].

\subsection{Benzoylation of $(+)$-catechin [12]}

$(+)$-Catechin was benzoylated in alkaline solution by benzoyl chloride. The reaction product after purification and recrystallization from acetone gave melting point $171-2^{\circ} \mathrm{C}$. The melting point indicated it to be pentabenzoyl ester of (+)-catechin [13].

\section{Results and Discussions}

The method of isolation and separation for $(+)$-catechin described in this report was found more convenient compared to others process [7, 14, 15]. The conventional methods involve multi steps process which was not economically feasible. Isolation process of the present work involves lesser steps and yield was found good.

Thin layer chromatographic [9] behavior of the isolated (+)-catechin was in good agreement with the authentic (+)-catechin. The compound showed absorption bands at 220 and $277 \mathrm{~nm}$ in the ultraviolet [16]. Anthocyanins give an absorption band at 275-280 $\mathrm{nm}$ regions. This ultraviolet behavior indicated the possibility of the isolated compound belonging to the flavonoid group. The mass spectra of $(+)$-catechin with its different fragments are understandable. The molecular mass of $(+)$-catechin is 290 . In the spectra the maxima $\mathrm{m} / \mathrm{z}$ ratio showed at 290 . The IR spectra of $(+)$-catechin has a broad band around $3400-2600 \mathrm{~cm}^{-1}$ region corresponding to aliphatic and aromatic $\mathrm{C}-\mathrm{H}$, phenolic and alcoholic $\mathrm{O}-\mathrm{H}$ stretching. A band at $1620 \mathrm{~cm}^{-1}$ observed may be due to aromatic $\mathrm{C}=\mathrm{C}$ 
stretching. Other stretchings were comparable with IR spectra of authentic $(+)$-catechin. The ${ }^{1} \mathrm{H}$-NMR spectra of + )-catechin was very clear and understandable. The observed signals in NMR spectra were in good agreement with the authentic (+)-catechin [17]. (+)Catechin molecule contains 15 carbons. In the ${ }^{13} \mathrm{C}$-NMR spectra, signals appeared at $\delta$ 27.7, 66.3, 80.9, 93.9, 95.1, 114.5, 115.1, 118.4 due to C-4, C-3, C-2, C-8, C-2́, C-5́, C-6́ carbons respectively and others aromatic carbons showed peaks at $\delta 99.1,130.6,144.6$, $144.8,155.3,156.1$ and 156.4. These data were also in good agreement with the authentic $(+)$-catechin [17].

Further, the isolated (+)-catechin on fusion [11] with $50 \%$ alcoholic $\mathrm{KOH}$ produced phloroglucinol and protocatechuic acid clearly indicated that the hydroxide functional groups are present in (+)-catechin at C-3, C-5, C-7, C-3 and C-4 positions (Fig. 1). The melting point of phloroglucinol and protocatechuic acid obtained from the alkali fusion reaction of $(+)$-catechin are $220{ }^{\circ} \mathrm{C}$ and $199{ }^{\circ} \mathrm{C}$, respectively. These melting point values agree well with literature values $[18,19]$. Furthermore chemical reactions of $(+)$-catechin also confirm the structure of $(+)$-catechin. For example, methylation and benzoylation of $(+)$-catechin gave 5,7,3,4-tetra methyl ether of $(+)$-catechin and pentabenzoyl ester of (+)-catechin respectively (Fig. 2).

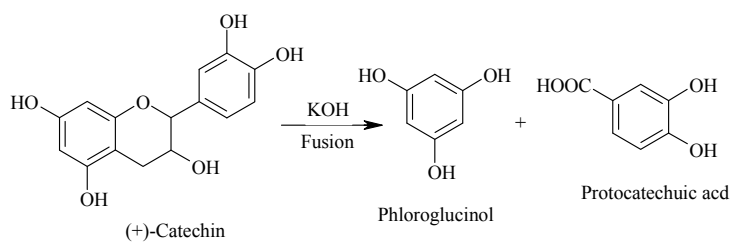

Fig. 1. Fusion products of $(+)$-catechin.

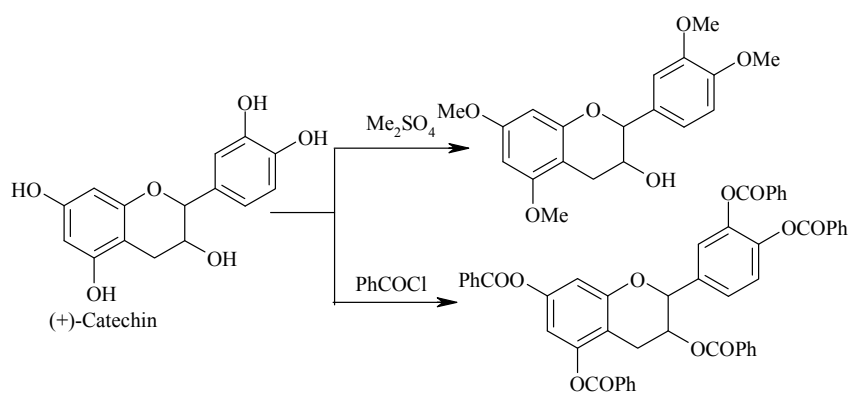

Fig. 2. Methylation and benzoylation products of $(+)$-catechin.

Different spectral analysis and chemical investigation of the isolated $(+)$-catechin are in good agreement with the structure of authentic sample of $(+)$-catechin which is shown in Figs. 1 and 2. 


\section{Conclusion}

The method of isolation of $(+)$-catechin presented here is very simple and gives better yield. It may be isolated commercially for several uses specially for making different natural dyes for textiles, leather, wool and silk fiber and medicinal purposes.

\section{Acknowledgements}

The authors wish to express their sincere thanks to Professor Atta-ur-Rahman, H.E.J. Research Institute of Chemistry, University of Karachi, Pakistan for his kind cooperation for recording spectral data. The authors also thank Md. Abul Hossain, Laboratory attendant, for his help in the progress of the work.

\section{References}

1. S. S. Bhatnagar, The Wealth of India, C.S.I.R., India 1, 8 (1948).

2. Atta-ur-Rahman, Hakim Mohammed Said, and Viqaruddin Ahmad, Pakistan Encyclopaedia Planta Medica, Hamdard Pakistan 1, 51 (1986).

3. M. O. Faruq, R. K. Sarker, and M. E. Haque, Bangladesh J. Sci. Ind. Res., XIV (1-2), 70 (1979).

4. F. Blum, American Chemical Abstracts 27, 5385 (1933).

5. L. H. Meyer, Food Chemistry (Reinhold Publishing Corporation, New York, 1960) pp 250-251.

6. H. B. Higby, J. Am. Pharm. Assoc. 32, 74 (1943).

7. M. S. Ali, R. K. Sarker, M. A. Hye, M. I. H. Mondal, Mozaffar Rahman, M. A. Ahsan, and M. A. Rahman, Bangladesh J. Sci. Ind. Res., XXVII (2), 146 (1993).

8. M. S. Ali, M. A. Hye, M. I. H. Mondal, and M. A. Rahman, Bangladesh J. Sci. Ind. Res., XXVI (1-4), 173 (1991).

9. E. Stahl, Thin Layer Chromatography, International Student Edition (Springer-Verlag, 1969) p. 719 .

10. K. N. Rai and R. A. Dasaundhi, J. Bangladesh Acad. Sci. 14, 58 (1990).

11. A. I. Vogel, Elementary Prac. Org. Chem. Part I, Small Scale Preparations, $2^{\text {nd }}$ Ed., (Longmanns, 1967) p. 311.

12. A. I. Vogel, Elementary Prac. Org. Chem. Part II, Qualitative Organic Analysis, $2^{\text {nd }}$ Ed. (Longmanns, 1966) p. 82.

13. Dictionary of Organic Compounds, $4^{\text {th }}$ edition, vol. 1, eds. J.R.A. Pollock and R. Stevens (Eyre and Spottiswoode Publisher Ltd., London, 1965) p. 572.

14. S. S. Bhatnagar, The Wealth of India, C.S.I.R., India 1, 8 (1948).

15. M. H. Khundkar, Science and Industry, 2, 309 (1964).

16. J. W. Clark-Lewis, L. M. Jackman, and T. M. Spotswood, Aust. J. Chem., 17, 632 (1990).

17. F. Nikkon, M. E. Haque, M. A. Islam, and M. Qaisuddin, J. Bio-sci. 3, 99, (1995).

18. Dictionary of Organic Compounds, $4^{\text {th }}$ edition, vol. 5, eds. J.R.A. Pollock and R. Stevens (Eyre and Spottiswoode Publisher Ltd., London, 1965) p. 2737.

19. Dictionary of Organic Compounds, $4^{\text {th }}$ edition, vol. 2, eds. J.R.A. Pollock and R. Stevens (Eyre and Spottiswoode Publisher Ltd., London, 1965) p. 1056. 